\title{
Ultra wideband antenna for high data rate applications
}

\author{
MonaGoyal $^{1}$, Dr. Balraj Singh Sidhu ${ }^{2}$ \\ PG Student, Electronics and Communication Engineering Department, Giani Zail Singh PTU Campus,Bathinda, India ${ }^{1}$ \\ Professor, Electronics and Communication Engineering Department, Giani Zail Singh PTU Campus, Bathinda, India ${ }^{2}$
}

\begin{abstract}
In this paper, a pentagon shaped ultra-wideband (UWB) antenna is proposed and developed for wireless communication systems. This antenna has low profile, light weight and has successfully demonstrated multiband and broadband characteristics. The simulated results show that proposed antenna has very good performance in impedance bandwidth and radiation pattern. A better impedance bandwidth is obtained from $3.1 \mathrm{GHz}$ to $13.48 \mathrm{GHz}$ that constitutes a fractional bandwidth of $125 \%$ with return loss less than or equal to $-10 \mathrm{~dB}$ (VSWR $<2$ ). The comparative results reveal that the proposed antenna possesses wider bandwidth than the earlier published structure. This designed antenna can be used for any wireless UWB device for high data rate applications.
\end{abstract}

Key words: Microstrip patch antenna, Ultra-wide band, Returns Loss, Input Impedance

\section{INTRODUCTION}

Antenna is the important part in any wireless communication system. The definition of antenna according to the IEEE Standard is defined as a mean for radiating or receiving radio waves [13]. In the other

fairly well established in terms of design and modeling, and workers were turning their attentions to improving antenna performance features (e.g., bandwidth), and to the increased application of the technology. Microstrip antenna falls into the category of printed antennas: radiating elements that utilize printed circuit manufacturing processes to develop the feed and radiating structure. Of all the printed antennas, including dipole, slots, and tapered slots; Microstrip antenna is by far the most popular and adaptable. This is because of all its salient features: including ease of fabrication, good radiation control, and low cost of production. The microstrip antenna is constructed from dielectric substrate, patch metal and the portion of the metallization layer is responsible for radiation [1].

Advance telecommunication system requires antennas with wider bandwidth and smaller dimensions than conventionally possible. Ultra-wideband (UWB) systems enable personal area network wireless connectivity since the Federal Communications Commission (FCC) released the frequency band from 3.1 to $10.6 \mathrm{GHz}$ for high data rate communication in 2002 [2]. Besides the demand for small size and compact profile antennas, broadband antennas are often required in order to cover simultaneously several bands. If a single antenna can operate in ultra-wideband that can cover multi-band applications, the necessity for multiple-single frequency antennas is not required. With this approach, applications requiring different frequencies can be operated simultaneously with only one multi-band antenna, which significantly reduces the circuit size. The major advantage of the UWB communication is to use the large bandwidth and capable of working in harsh communication environments with low SNRs. In the narrow band communication, the fading which is caused by reflected signal from various things is the unavoidable
Words, antenna is a transducer between a guided wave in a transmission line and an electromagnetic wave propagating in unbounded region. By the early 1980s basic microstrip antenna elements and arrays were phenomenon and it can make the received signal weak up to $-40 \mathrm{~dB}$.Zhu et al. has proposed a novel planar ultrawideband antenna with dual band-notched characteristics. The antenna was fabricated on a printed circuit board (PCB), having a circular monopole and arc-shaped parasitic strips on one side and a ground plane with a slot aperture on the other side. Two narrow bands at $5.15 \mathrm{GHz}$ and $5.725 \mathrm{GHz}$ were notched by using two arc-shaped parasitic strips on the same layer of the radiator. Surface current distributions and equivalent circuit model were applied to analyze the operating principle of the proposed antenna [1]. Linardou et al. in [2] has described that an ultra-wideband communication technique has been paid much attention for short range and high speed wireless communications since the Federal Communications Commission (FCC) allocated the frequency band from 3.1-10.6 GHz. Therefore, UWB antennas provide the feature of wide-band reception for different wireless standard. Allen et al. reported that as compared to the classical broadband antennas, for example a straight wire monopole features a simple structure but it bandwidth is only around $10 \%$ and the Vivaldi antenna is a directional antenna hence it is unsuitable for indoor systems and portable devices [3]. Chen et al. in 2005 were successfully proposed a circular ring monopole antenna with UWB applications. It has been demonstrated that circular ring antenna can satisfy the critical requirements for UWB antennas [4]. William and Nakkeeran in [5] presented the design and analysis of a new coplanar waveguide (CPW) fed ultra-wideband (UWB) slot antenna. An extensive analysis of the proposed antenna in the frequency and time domains were presented. The antenna was fabricated using FR4 substrate and characterized by measuring return loss, radiation pattern and gain. A better impedance bandwidth was obtained from $3.1 \mathrm{GHz}$ to $11.4 \mathrm{GHz}$ that constitutes a fractional bandwidth of $114 \%$ with return 
loss less than or equal to $-10 \mathrm{~dB}(\mathrm{VSWR}<2)$. Time domain analysis of the antenna is also performed that witnessed the linear phase and less distortion. Another study available in [6] described that slot antennas are of major importance because of its simple and miniaturized structure which provides ultra-wideband configurations. A. H. M. Zahirul Alam, Rafiqul Islam, and Sheroz Khan (2007) successfully proposed an antenna in [7]. This article reported that the behavior of the antenna is influence by the feed width, position of the feed line and the partial ground plane size. The analysis showed UWB antenna can be obtained by optimizing these parameters. Wen-junlu et al. in [8] reported a stable omnidirectional radiation pattern with good polarization purity and flat gain performance using half-folded anti-podal printed slot antenna. To design an antenna to operate in the UWB band is quiet challenging one because it has to satisfy the requirements such as ultra-wide impedance bandwidth, omnidirectional radiation pattern, constant gain, high radiation efficiency, low profile, compact and easy manufacturing. Interestingly the planar slot antennas with CPW feeding possess the above said features hence CPW fed planar slot antennas are identified as the most promising design for wideband wireless applications. Recently, there are various types of UWB antennas which have been designed to achieve the requirement for different applications.

\section{ANTENNA DESIGN \& STRUCTURE}

The design of the microstrip patch is influenced by many dimensional parameters like length, width and height of the structure. The dimensions of the slot and electrical permittivity of the substrate also plays an important role to make an efficient antenna design. The flow chart of the design of proposed antenna is given in Figure 1. These steps have been strictly followed to obtain the optimal dimensional parameters of the proposed design.The proposed antenna in this paper is designed with a compact rectangular slot and a pentagon shape feeding structure at the interior portion of the feed. The basic geometry of proposed UWB antenna is shown in Figure 2. The proposed antenna is designed on FR4 substrate of thickness, $\mathrm{h}=1.6 \mathrm{~mm}$ with dielectric constant, $\mathrm{C}_{\mathrm{r}}=4.4$ The CPW feed is designed with $50 \Omega$ transmission line which consists of a single strip having width of $2.4 \mathrm{~mm}$ is used to feed the antenna. The patch size is characterized by the length $\mathrm{L}$, width $\mathrm{W}$, thickness $\mathrm{h}$, length of the slot Ls, width and gap between the ground plane and feed strip, The constructional parameters of the proposed antenna are detailed in Table 1 . The fields at the edges of the patch undergo fringing because the dimensions of the patch are finite along the length and width [1]. For better resonance performance parameters, good impedance matching is required and it can be calculated using equation (1) and (2) [1].

$$
\begin{aligned}
& \varepsilon_{\sigma \sigma}=\frac{\varepsilon_{r}+1}{2}+\frac{\varepsilon_{r}-1}{2}\left(\frac{1}{\sqrt{1+12 \frac{h}{w}}}\right) \\
& Z_{0}=\frac{120 \Pi}{\sqrt{\varepsilon_{e f f}}\left[\frac{w}{h}+1.393+0.667 \ln \left(\frac{w}{h}+1.444\right)\right]} \text { for } \frac{w}{h} \geq 1
\end{aligned}
$$

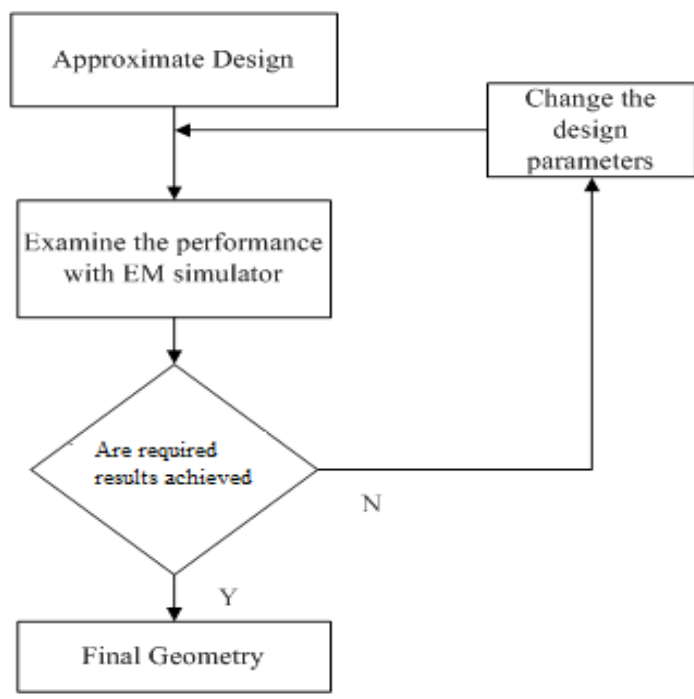

Figure 1 Flow chart of the design process

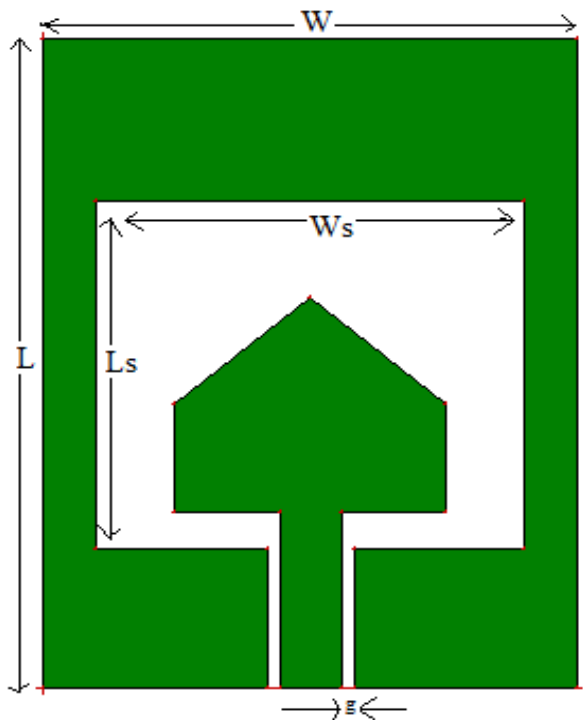

Figure 2 Geometry of the proposed antenna

Table 1 Constructional parameters of proposed structure

\begin{tabular}{|c|l|c|}
\hline S.no & Parameters & Dimensions \\
\hline 1 & Length of proposed Antenna, L & $28 \mathrm{~mm}$ \\
\hline 2 & Width of Proposed Antenna, W & $21 \mathrm{~mm}$ \\
\hline 4 & Length of slot, Ls & $15 \mathrm{~mm}$ \\
\hline 5 & Width of slot, Ws & $17 \mathrm{~mm}$ \\
\hline 6 & $\begin{array}{l}\text { Gap between the strip width and } \\
\text { ground plane, g }\end{array}$ & $0.5 \mathrm{~mm}$ \\
\hline 7 & Feed strip width & $2.4 \mathrm{~mm}$ \\
\hline
\end{tabular}

\subsection{Return Loss}

\section{RESULTS AND DISCUSSION}

S-parameters describe the input-output relationship between ports (or terminals) in an electrical system. Return loss is the difference between forward and reflected power, in $\mathrm{dB}$ [1].In order to access the effectiveness of the proposed design, developed methodology were used to draw the structure of antenna. 
The simulation tool adopted for evaluating the performance of the fractal antenna is IE3D software, which exploits the method of moments to solve the electric field integral equations. Figure 3 shows the S11 parameters of the proposed antenna. As expected, it was demonstrated that the CPW fed pentagon shaped tuning stub provide the ultra-wide bandwidth from $3.1 \mathrm{GHz}$ to $13.48 \mathrm{GHz}$. The proposed antenna resonates at $3.57 \mathrm{GHz}$, $6.59 \mathrm{GHz}, 9.09 \mathrm{GHz}, 11.19 \mathrm{GHz}$ and $13.03 \mathrm{GHz}$ frequencies of $\mathrm{S}, \mathrm{C}, \mathrm{X}$ and $\mathrm{Ku}$ band region. The simulated resonant performance characteristics of the proposed antenna are reported in Table 2 .

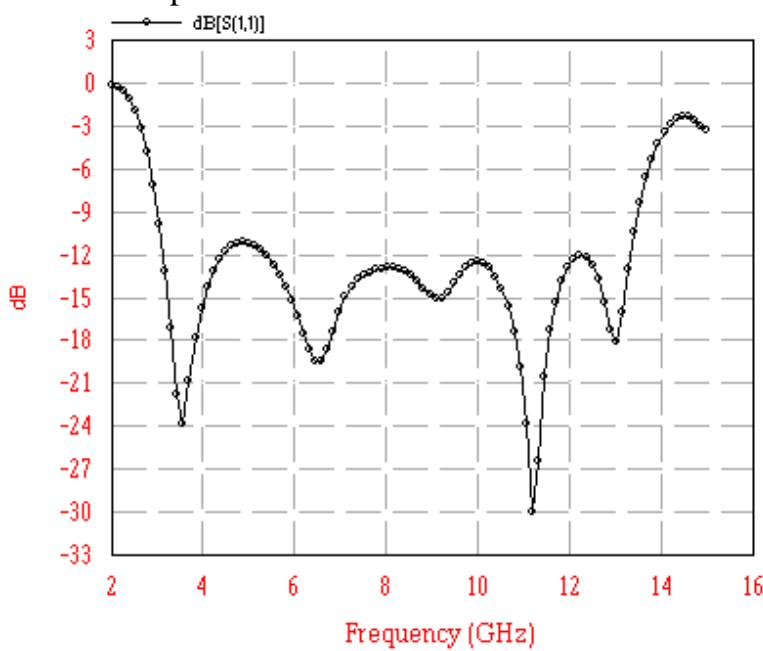

Figure 3 Resonating properties of the proposed antenna.

Table 2 Return loss of proposed antenna

\begin{tabular}{|c|c|c|}
\hline S. no. & $\begin{array}{c}\text { Resonating Frequency } \\
(\mathbf{G H z})\end{array}$ & $\begin{array}{c}\text { Return Loss } \\
(\mathbf{d B})\end{array}$ \\
\hline 1. & 3.57 & -23.94 \\
\hline 2. & 6.59 & -19.54 \\
\hline 3. & 9.09 & -15.13 \\
\hline 4. & 11.19 & -30.08 \\
\hline 5. & 13.03 & -18.11 \\
\hline
\end{tabular}

\subsection{Input Impedance}

Electromagnetic waves may encounter differences in impedance at each interface while traveling through the different parts of the antenna system, from the source to the feed line to the antenna and finally to the free space. The input impedance of an antenna is a complex function of frequency, which cannot be presented in any simple analytical form. The antenna terminal impedance at a single frequency may be accurately described by a resistance in series with a reactance as given in equation (3). The degree of mismatch is a function of input impedance and characteristic impedance of the line as given in equation (4), where $Z_{c}$ is the characteristic impedance of the transmission line and $\Gamma$ is the voltage reflection coefficient at the antenna input terminals. It determines the amount of incident or available power which is reflected at the input antenna terminals in to the

line [11]. $Z_{\mathrm{MK}}=R_{\mathrm{MK}}+j\left(\omega L_{\mathrm{MK}}-\frac{1}{\omega C_{\mathrm{MK}}}\right)$

$$
Z_{\mathbf{M K}}=Z_{\mathbf{C}}\left[\frac{1+|\Gamma|}{1+|\Gamma|}\right]
$$

The impedance of the antenna has been adjusted through the design process to be matched with the feed line and have less reflection to the source. A typical input impedance characteristic of the proposed antenna is shown in Figure 4 and 5.

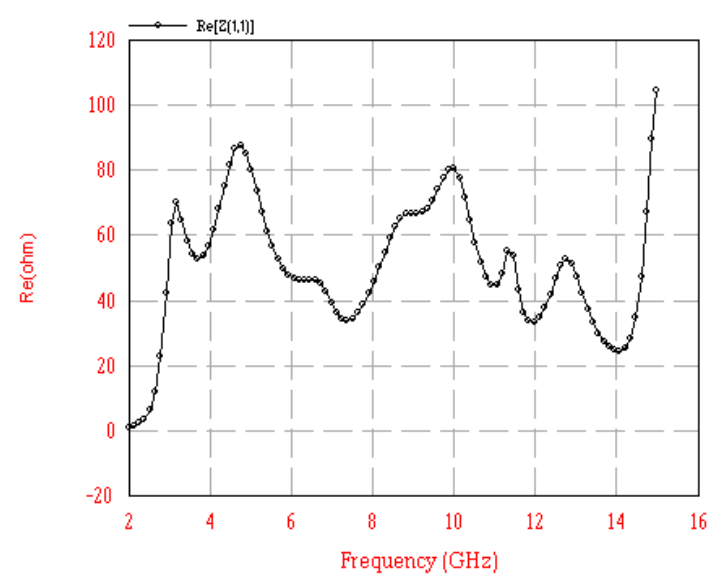

Figure 4 Simulated real input impedance of the proposed antenna

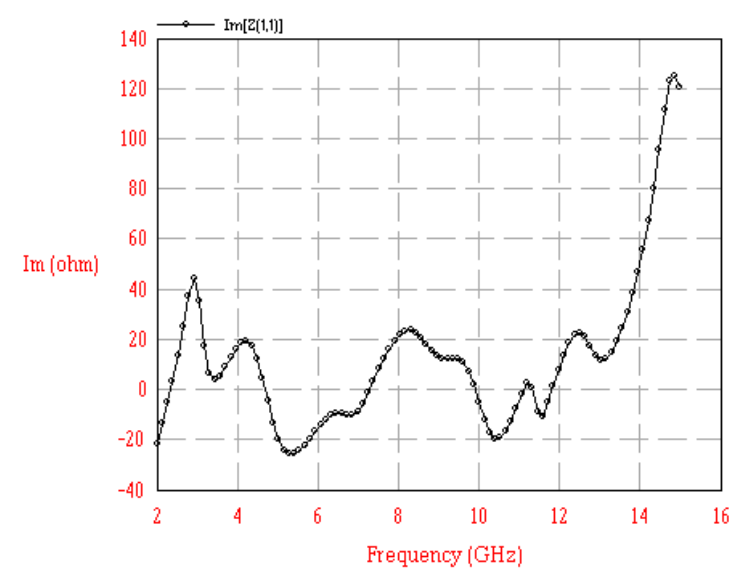

Figure 5 Simulated imaginary input impedance of the proposed antenna

Table 3 Input Impedance of proposed antenna

\begin{tabular}{|c|c|c|}
\hline $\begin{array}{c}\text { S. } \\
\text { no. }\end{array}$ & $\begin{array}{c}\text { Resonating Frequency } \\
(\mathbf{G H z})\end{array}$ & $\begin{array}{c}\text { Input } \\
\text { Impedance } \\
\text { (ohms) }\end{array}$ \\
\hline 1. & 3.57 & $53.75+\mathrm{j} 5.43$ \\
\hline 2. & 6.59 & $46.11-\mathrm{j} 9.40$ \\
\hline 3. & 9.09 & $66.52+\mathrm{j} 12.19$ \\
\hline 4. & 11.19 & $48.09+\mathrm{j} 2.40$ \\
\hline 5. & 13.03 & $46.99+\mathrm{j} 11.72$ \\
\hline
\end{tabular}

\subsection{VSWR}

Basically the voltage standing wave ratio (VSWR) is a measure of the impedance mismatch between the transmitter and the antenna. Large value of VSWR corresponds to the high mismatch. Minimum value of 
VSWR corresponds to a perfect match that is taken as unity. The VSWR v/s frequency plot for the proposed antenna is shown in Figure 6. It may be observed that the values of the VSWR are less than 2 for the whole band which is within the required limits, as given in Table 4

Table 4 VSWR of proposed antenna

\begin{tabular}{|c|c|c|}
\hline S. no. & $\begin{array}{c}\text { Resonating Frequency } \\
(\mathbf{G H z})\end{array}$ & VSWR \\
\hline 1. & 3.57 & 1.13 \\
\hline 2. & 6.59 & 1.23 \\
\hline 3. & 9.09 & 1.42 \\
\hline 4. & 11.19 & 1.06 \\
\hline 5. & 13.03 & 1.28 \\
\hline
\end{tabular}

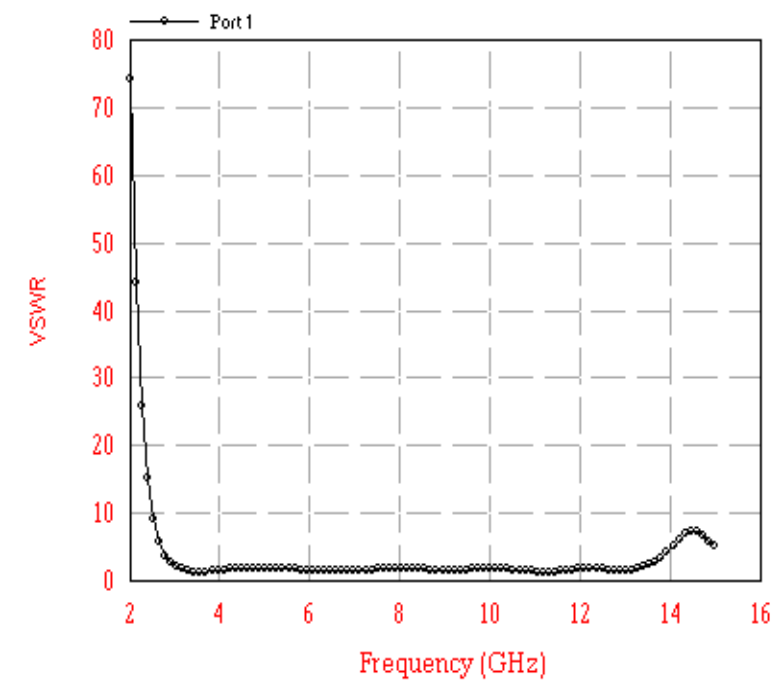

Figure 6 Simulated VSWR of the proposed antenna.

\subsection{Smith Chart}

The Smith Chart is a fantastic tool for visualizing the impedance of a transmission line and antenna system as a function of frequency. The Smith Chart, invented by Phillip H. Smith (1905-1987), is a graphical aid specializing in radio frequency (RF) engineering to assist in solving problems with transmission lines and matching circuits. The Smith Chart is plotted on the complex reflection coefficient plane in two dimensions and is scaled in normalized impedance (the most common), normalized admittance or both, using different colors to distinguish between them. These are often known as the Z, Y and YZ Smith Charts respectively. Figure 7 shows the smith chart of the proposed antenna at required working frequencies.

\subsection{Radiation Patterns}

Radiation pattern is the graphical representation of the field pattern of radiation from an antenna as a function of direction /space coordinates. The radiation pattern of an antenna may be very narrow, very wide, omni shaped, shaped beam or tilted beam type. Also, the radiation patterns may have single beam or multiple beams. These beams may be steered mechanically or electronically. A radiation pattern defines the variation of the power radiated by an antenna as a function of the direction away from the antenna. This power variation as a function of the arrival angle is observed in the far field.

Figure 8 shows the simulated radiation patterns of the proposed structure. It is observed that the proposed antenna exhibits omnidirectional radiation patterns at the $y-z$ plane (H-plane) and "8-shape" radiation patterns at the $\mathrm{X}-\mathrm{z}$ plane (E-plane), similar to those of an ideal dipole antenna. It is illustrated that simulated and measured radiation characteristics are in good agreement and the proposed antenna is linearly co-polarized.

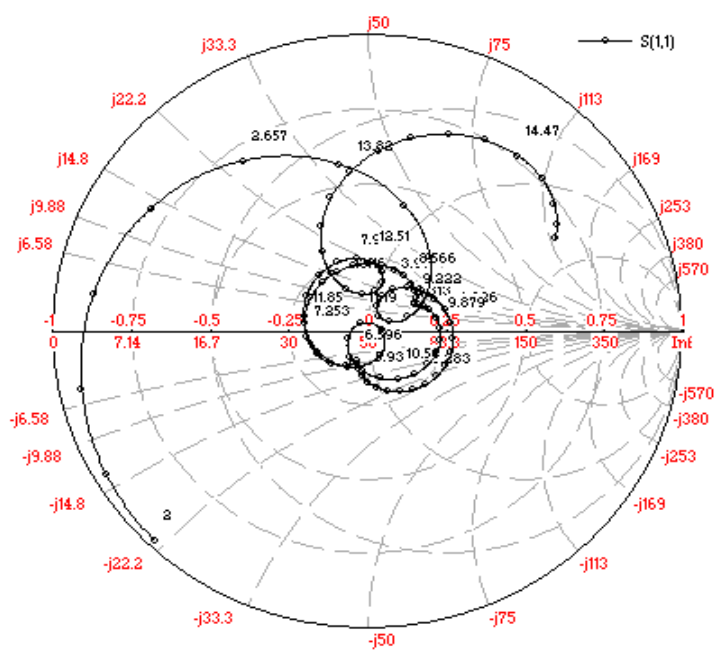

Figure 7 Smith Chart of the proposed antenna.

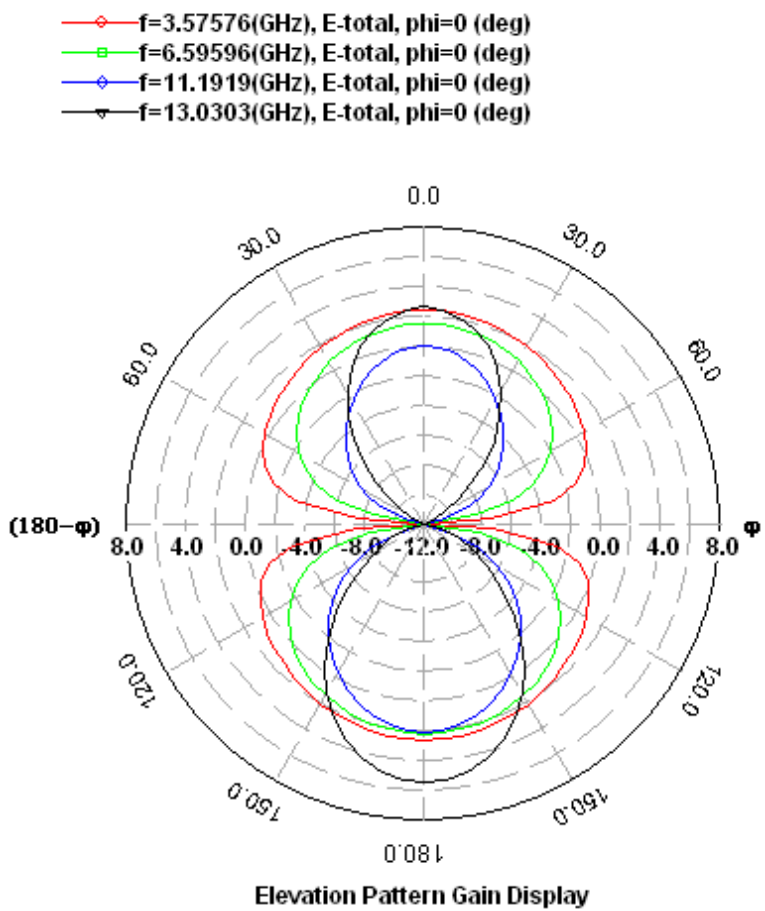

(a) 

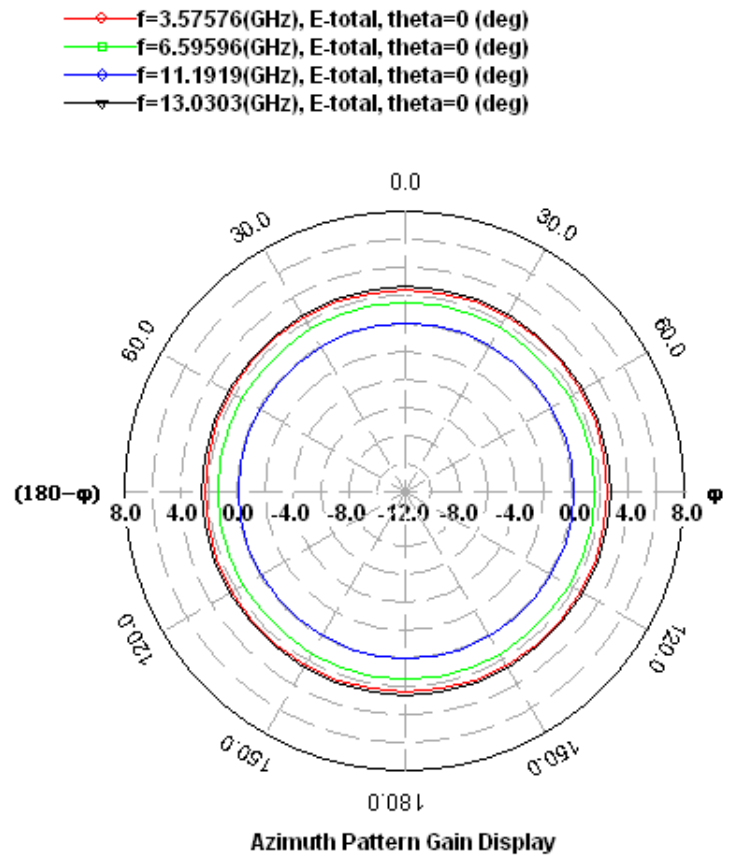

(b)

Figure 8 Simulated radiation patterns of proposed antenna in (a) E-plane (b) H-Plane.

\subsection{Analysis of propose antenna with varying} height of the substrate

The performance of the microstip patch antenna is very much dependent on the dimensions of the patch. The height of the substrate is among one of the important dimensional parameter. The performance of the proposed antenna by varying the height of the substrate has been extensively analyzed and associated s-parameter results are shown in Figure 9.

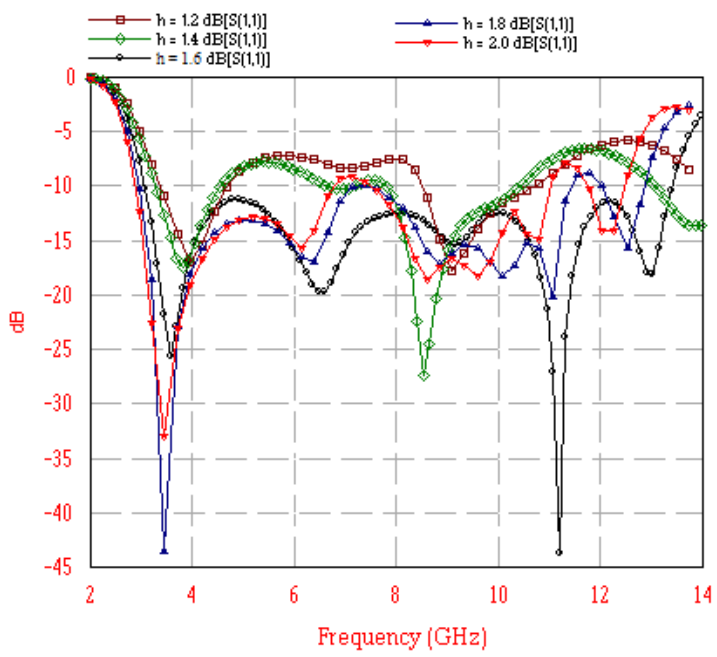

Figure 9 Simulated results of the proposed antenna by varying height of substrate

\subsection{Comparison with published work}

In [5] author has presented a simple antenna with minimal size and better impedance matching. A triangular tuning stub has been introduced at the interior portion of the slot for enhancing the coupling between slot and feed. In the similar approach, a pentagonal shape tuning has been designed and proposed in this research work to further enhance the impedance matching and bandwidth of the proposed antenna. For fair comparison the dimensional parameters of the antenna has kept constant. The detailed comparison of both the structures is given in below table. It may be observed from the results that the proposed structure has better impedance matching and wider bandwidth than the structure presented in the earlier published work. The bandwidth of the published triangular tuning stub antenna was $114 \%$ and the bandwidth of the proposed pentagonal tuning stub antenna is $125 \%$. This increase in the bandwidth is because of the better impedance matching of the proposed tuning stub with the feed configuration and resultant magnetic currents of the structure. It may also notice that the return loss for the corresponding frequencies for both the structure shows the similar behavior but the proposed antenna possesses additional frequency band (12.0-13.48 $\mathrm{GHz}$ ) of $\mathrm{Ku}$ region with center frequency $13.03 \mathrm{GHz}$ which can be used for various wireless applications such as radar and satellite communication.

Table 5 Comparison of published [5] and proposed work

\begin{tabular}{|c|c|c|c|c|}
\hline $\begin{array}{c}\text { Name of } \\
\text { the } \\
\text { Antenna }\end{array}$ & $\begin{array}{c}\text { Antenna } \\
\text { Geometry }\end{array}$ & $\begin{array}{c}\text { Resonating } \\
\text { Frequency } \\
\text { (GHz) }\end{array}$ & $\begin{array}{c}\text { Retur } \\
\text { n Loss } \\
(d B)\end{array}$ & $\begin{array}{c}\text { Bandwidth } \\
\text { (percentag } \\
\text { e) }\end{array}$ \\
\hline \multirow{4}{*}{$\begin{array}{l}\text { UWB slot } \\
\text { antenna } \\
\text { with } \\
\text { triangular } \\
\text { tuning stub } \\
\text { [5] }\end{array}$} & & 3.50 & -21.2 & \multirow[t]{4}{*}{$\begin{array}{c}114 \% \\
(3.1-11.4 \\
\mathrm{GHz})\end{array}$} \\
\hline & & 6.50 & -25.0 & \\
\hline & & 9.30 & -21.2 & \\
\hline & & 11.2 & \begin{tabular}{|l|}
-33.0 \\
\end{tabular} & \\
\hline \multirow{5}{*}{$\begin{array}{l}\text { UWB slot } \\
\text { antenna } \\
\text { with } \\
\text { pentagonal } \\
\text { tuning stub }\end{array}$} & & 3.57 & -23.94 & \multirow{5}{*}{$\begin{array}{c}125 \% \\
(3.1-13.48 \\
\text { GHZ) }\end{array}$} \\
\hline & & 6.59 & $\begin{array}{c}- \\
19.54\end{array}$ & \\
\hline & & 9.09 & $\stackrel{-}{15.13}$ & \\
\hline & & 11.19 & $\begin{array}{l}- \\
30.08\end{array}$ & \\
\hline & & 13.03 & $\begin{array}{c}- \\
18.11\end{array}$ & \\
\hline
\end{tabular}

\section{CONCLUSION}

In this work, the pentagon shape has been considered as the candidate structure utilized to form the tuning stub in the slot of proposed antenna. The presented results reveal that the proposed antenna is capable to possess UWB characteristics that make it feasible for wireless high data rate applications.

A fair comparison of the proposed antenna with the published work has described that the presented structure outperforms its competitor in terms of impedance bandwidth. The bandwidth of the published triangular tuning stub antenna was $114 \%$ and the bandwidth of the proposed pentagonal tuning stub antenna is $125 \%$. These resonating characteristic make the proposed antenna feasible for UWB wireless applications. 


\section{REFRENCES}

[1] F. Zhu, S. Gao, A. T. S. Ho, C. H. See, R. A. Abid-Alhameed, J. $\mathrm{Li}$ and $\mathrm{J} . \mathrm{Xu}$, "Design and Analysis of Planar Ultra Wideband Antenna with Dual Band Notching Function," Progress In Electromagnetics Research, vol. 127, pp. 523 - 536, 2012.

[2] I. Linardou, C. Migliaccio, J. M. Laheurte and A. Papiernik. Twin Vivaldi antenna fed by coplanar waveguide. IEEE Electronics Letters, 23rd October, 1997, vol.33, no. 22, pp. 1835-1837.

[3] Ben Allen, MischaDohler, Ernest E. Okon, Wasim Q. Malik , Anthony K. Brown and David J. Edwards, "Ultra-wideband Antennas and Propagation fir Communications", Radar and Imaging, Wiley 2007.

[4] X. Chen, Member, J. Liang, P. Li, L. Guo, C. C. and C. G. Parini, "Planar UWB monopole antennas", Proceeding of the IEEE APMC 2005, 2005.

[5] J. William and R. Nakkeeran, "CPW-Fed UWB Slot Antenna with Triangular Tuning Stub", International Journal of Computer and Electrical Engineering, Vol. 2, No. 4, August 2010.

[6] J. Jiang, Z. Yan, and C. Wang, "A Novel Compact UWB Notch Filter Antenna with a Dual - Y - Shaped Slot," Progress In Electromagnetics Research Letters, vol. 14, pp. 165 - 170, 2010.

[7] A.H.M ZahirulAlam, MdRafiqul Islam and Sheroz Khan, "Design and Analysis of Turning Fork Type UWB Patch Antenna", IEEE Transactions on Applied Electromagnetic, 2007.

[8] W. Lu, Y. Cheng and H. Zhu, "Novel Wideband Antipodal Slot Antenna with improved Cross - Polarization Performance," IEEE ICCS vol. 1, pp. $384-387,2008$.

[9] C. A. Balanis, "Antenna Theory Analysis and Design". 